\title{
IMPROVED ANALYTICAL METHOD FOR ESTIMATION OF ESSENTIAL OIL IN DRUG OINTMENT THROUGH RAPID STATIC CHROMATOGRAPHY HEADSPACE FOR QUALITY CONTROL ANALYSIS
}

\author{
DHIR NK ${ }^{1 *}$, JOSHI $M^{2}$, KAUR V ${ }^{1}$ \\ ${ }^{1}$ Department of Chemistry, Chandigarh University, Gharuan, Mohali - 140413, Punjab, India. ${ }^{2}$ Department of Biotechnology, Chandigarh \\ University, Gharuan, Mohali - 140 413, Punjab, India. Tel.: +918894003786. Email: dhirnandu@yahoo.co.in
}

Received: 26 October 2017, Revised and Accepted: 31 January 2018

\begin{abstract}
Objective: The objective for new methodology was to develop a rapid analytical method for drug quantification in ointment samples and eliminate the usage of hazardous solvents in the sample and standard preparation, less elution time of component of interest to sustained green chemistry applications.
\end{abstract}

Methods: Headspace (HS) chromatography was used along with gas chromatography (GC) having direct sample treatment with the help of calibration slope method.

Results: All essential oil (EO) was well separated from each other and eluted 1.6 times faster from traditional classical GC method. The present method does not require any hazardous solvents for sample preparation.

Conclusion: This method provides the accurate and precise results for EO added in ointment samples and can be used for routine quality control testing before releasing the final product release for the consumers.

Keywords: Essential oil, Gas chromatography, Headspace, Greener method and quality control.

(c) 2018 The Authors. Published by Innovare Academic Sciences Pvt Ltd. This is an open access article under the CC BY license (http://creativecommons. org/licenses/by/4. 0/) DOI: http://dx.doi.org/10.22159/ajpcr.2018.v11i5.23351

\section{INTRODUCTION}

Quality control testing in any pharmaceutical and health-care industry was always a challenging job to release the product in time by taking all special care during analytical testing, i.e., usage of toxic solvents, gases, and appropriate disposal for these experimental wastage [1]. Gas chromatography (GC) is frequently used for the estimates these oil contents used in the preparation of different products manufactured in pharmaceutical industries [2]. As essential oils (EOs) have medicinal value and used in the pharmaceutical industries for the manufacturing of various types of ointment, these oils are natural and having more impurities, which sometimes give erratic results during drug estimations and resulted out of specification (OOS). Due to these impurities, the method specificity was also challenges to get reliable results include complex sample preparation [3,4]. In current scenario, the EO estimation is the challenge in pharmaceutical Quality control lab due to complex sample preparation and usage of classical GC techniques, but no headspace (HS)GC method is reported till date for these types of formulation. The major limitations for existing GC classical method have been described below as:

Complex sample preparation with the usage of chloroform as well as poor specificity in existing GC analytical methods lead to give OOS results during routine analysis. High elution time for a component of interest (about $45 \mathrm{~min}$ ) for completion of single chromatography run deeply impacts the industry in terms of economic terms. The Traditional analytical method is not capable to separate unspecified impurity with the help of GC method. As it has been reported that there are many unspecified natural impurities, peaks of solvents used for sample preparation, and other ingredients peaks reported in chromatogram which cause coelution and erratic assay values.

To overcome all above discrepancy the innovative analytical method is optimized and partially validate in HS chromatography without the usage of any solvents for standard and sample preparation, i.e., direct samples explore to HS vial and inject to obtained precise and accurate results with shortest runtime to avoid diluents peak interference. Multilevel calibration curve is drawn to calculate each individual drug component. HS-GC is the most popular and rapid techniques for the analysis of major EO which are volatile in solid, liquid, and gas samples. In brief, the volatile components in the liquid or solid sample are transferred to a closed vial and kept to reach equilibrium between the sample and the vapor in the HS. A fraction of the HS vapor is sampled and introduced into a GC System. Injection of the analytes evaporated from the sample into the GC system could minimize the contamination of the instrument and deterioration of the GC capillary column [5-9].

In the present research work, estimation of EO is done by HS chromatography with direct injection of standards and test with no uses of preparation and usage of toxic solvents for sample preparation. The EOs used are oil of wintergreen (Methyl salicylate), Tarpin ka Tel (Pinene), Nilgiri Tel (Eucalyptus), and Pudinah ke Phool (Menthol) which is used in the manufacturing of pain relief ointment. The present research work is done to concern with the green chemistry to develop an analytical procedure and overcome the limitations of traditional methods causes exposure of solvents and gases to environment and safety of analytical chemist $[10,11]$.

\section{Tarpin ka Tel (pinene)}

It is isomer mixture of pinene based molecule and having molecular formula $\mathrm{C}_{10} \mathrm{H}_{16}$ and molecular weight $136 \mathrm{~g} / \mathrm{mol}$. It is a transparent, colorless, or pale yellow liquid and has rosin irritating odor properties. It is soluble in alcohol, ether, benzene, chloroform, carbon disulfide, acetic acid, and organic solvents such as carbon tetrachloride; it has been used in varies the industrial application of organic synthesis, extraction fractionation turpentine by pinene, preparation of antiseptic ointment, synthetic borneol, and adhesives's original team [12]. 
Nilgiri Tel (eucalyptus)

Eucalyptol is a natural organic compound found in a colorless liquid. It is cyclic ether and a monoterpenoid. Many synonyms for eucalyptol is used for identification, namely, 1,8-cineol, 1,8-cineole, 1,8-epoxy-p-menthane, 1,8-oxido-p-menthane, eucalyptol, eucalyptol, 1,3,3-trimethyl-2-oxabicyclo[2,2,2]octane, cineol, cineole, and Nilgiri Tel as per Ayurvedic Pharmacopoeia. This drug is insoluble in water, miscible with ether, ethanol, and chloroform having molecular formula $\mathrm{C}_{10} \mathrm{H}_{18} \mathrm{O}$ with molecular weight $154.249 \mathrm{~g} / \mathrm{mol}$. Drug is used in a cream, ointment, and lotion for prepared for pain relief and for speeding up the healing of wounds and ulcers [13].

\section{Oil of wintergreen (methyl salicylate)}

Methyl salicylate (oil of wintergreen or wintergreen oil) is an organic ester naturally produced by many species of plants, particularly wintergreens. Oil of wintergreen is miscible in diethyl ether, ethanol, glacial acetic acid, and soluble in chloroform having molecular formula $\mathrm{C}_{8} \mathrm{H}_{8} \mathrm{O}_{3}$ with molecular weight $152.1494 \mathrm{~g} / \mathrm{mol}$. The drug is used for temporary relief of minor aches and pains caused by arthritis, simple backache, strains, sprains, and bruises. Methyl salicylate/menthol cream is a topical analgesic [14].

\section{Pudinah ka Phool (Menthol)}

Menthol is an organic compound and can be prepared by synthetically or obtained from corn mint, peppermint, or other mint oils. It is a waxy, crystalline substance, clear, or white in color having slightly solubility in water. It is used mostly in pain relief, anti-inflammatory ointments. Menthol is volatile in nature, having formula $\mathrm{C}_{10} \mathrm{H}_{20} \mathrm{O}$ with molecular weight $156.27 \mathrm{~g} / \mathrm{mol}$. [15].

\section{MATERIALS AND METHODS}

\section{Reagent and Solvents}

No solvents used for standard and test preparation, i.e., direct weighing for component of interest and injection for mixtures of standards and test separately to HS-GC. The reference materials are used from (Indian Pharmacopoeia, 2017) IP their purity used 99.0\% for reference standard. Perkin Elmer's GC, Elite-624, 30 m (Length) $\times 0.53 \mathrm{~mm}$ (id), $3 \mu$ (thickness) capillary column were used throughout the experiment.

\section{Equipment}

Throughout the measurements and quantifications, Perkin Elmer's Clarus 580 with turbo $40 \mathrm{HS}$ sampler was used with Empower software from Waters Ltd., MILFORD, MA 01757 USA was employed.

\section{Chromatographic conditions}

The EO samples were analyzed by HS-GC - $400.25 \mu \mathrm{m}$. Helium was used as a carrier gas. The conditions used for HS-GC are given in Tables 1 and 2, respectively.

\section{Standard and test preparation}

\section{Standards calibration curve}

Density of standard solutions weighing in $\mathrm{g} / \mathrm{ml}$ and observed for Tarpin ka tel (Pinene), Nilgiri katel Eucalyptol Pudinah ke phool (Menthol), and Oil of wintergreen (methyl salicylate) is $0.86 \mathrm{~g} / \mathrm{ml}, 0.900 \mathrm{~g} / \mathrm{ml}$, and $0.89 \mathrm{~g} / \mathrm{m}$ land $1.174 \mathrm{~g} / \mathrm{ml}$, respectively.

$1 \mathrm{ml}$ of each standard was taken into HS vial (for solid or wax, weight equivalent to $1 \mathrm{ml}$ based on density in $\mathrm{g} / \mathrm{ml}$ ) and was mixed by shaking to prepare a standard solution.

$10 \mathrm{mg}$ of microcrystalline wax (ingredients used in the ointment) was taken into HS vial and spike $1 \mu \mathrm{l}$ of above standard into it and crimped and treated this as standard, which was used for calculation of test concentration as given below:

$$
\text { Amountinmg of eachanalytein } 1 \mu \mathrm{l}=\frac{\begin{array}{l}
\text { Density of standard } \\
\text { component }\left(\frac{\mathrm{g}}{\mathrm{ml}}\right)
\end{array}}{\begin{array}{l}
\text { Noof components } \\
\text { in mixture }
\end{array}} \times \frac{1}{1000}
$$

Table 1: GC conditions

\begin{tabular}{ll}
\hline Parameters & Conditions \\
\hline Instrument & Perkin Elmer Clarus $580 \mathrm{GC}$ \\
Column & Elite-624, 30 m×0.53 mm, $3 \mu \mathrm{m}$ \\
Injector & Capillary split-split less injector (CAP) \\
Liner & $4 \mathrm{~mm}$ liner filled with Silanized wool \\
Injector temperature & $240^{\circ} \mathrm{C}$ \\
$\begin{array}{l}\text { Carrier gas and flow } \\
\text { rate }\end{array}$ & Helium $@ 3 \mathrm{~mL} / \mathrm{min}$ \\
Split (ratio) & $30: 1$ \\
Oven program & $80^{\circ} \mathrm{C}-1.0 \mathrm{~min}$ \\
& $12.5^{\circ} \mathrm{C} / \mathrm{min} .200^{\circ} \mathrm{C}-2.0$ min \\
& Runtime: 12.60 min \\
Detector & FID (range 20 , Attenuation -3) \\
Sample injection & $\mathrm{HS}$ no diluent is used (elimination of \\
diluent & $\mathrm{CHCl}$ which is used as diluents for the \\
& sample preparation) \\
\hline
\end{tabular}

HS: Headspace, GC: Gas chromatography, FID: Flame ionization detector

Table 2: HS chromatography conditions

\begin{tabular}{ll}
\hline Parameters & Conditions \\
\hline Instrument & Perkin Elmer Turbo \\
& Matrix 40 \\
Vial temperature & $160^{\circ} \mathrm{C}$ \\
Needle temperature & $170^{\circ} \mathrm{C}$ \\
Transfer line temperature & $180^{\circ} \mathrm{C}$ \\
GC cycle time & $20.00 \mathrm{~min}$ \\
Vial equilibration time & $30.00 \mathrm{~min}$ \\
Pressurization time & $2.0 \mathrm{~min}$ \\
Injection time & $0.05 \mathrm{~min}$ \\
Withdrawal time column pressure (PPC) & $0.2 \mathrm{~min} 15 \mathrm{Psi}$ \\
\hline
\end{tabular}

HS: Headspace, GC: Gas chromatography

Test preparation: $10 \mathrm{mg}$ of sample was taken into HS vial to crimp and run on HS-GC and flame ionization detector. In $1 \mu \mathrm{l}$ standard mix number of milligram of solvent present was calculated and response of each component in sample chromatogram was observed which was correlated with standard response to get the amount of each component present in $10 \mathrm{mg}$ of sample and multiply with 10 to get $\%$ of each in $100 \mathrm{mg}$ of sample (remove the area from Microcrystalline Wax from sample) as given below:

$\begin{aligned} & \text { Percentage }(\%) \text { of } \\ & \text { each analyte in sample }\end{aligned}=\frac{\text { Area in sample } \times \text { Amount in standard }}{\text { Area in standard }} \times 10$

Method validation approach

System precision and recovery studies have been conducted for HS-GC method.

\section{Protocol for calibration plot/linearity curve}

The standard stock solution was prepared same as per standard preparation procedure described in standard calibration curve preparation by mixing $1 \mathrm{ml}$ or equivalent to $1 \mathrm{ml}$ of each standard.

$1 \mu \mathrm{l}, 2 \mu \mathrm{l}, 3 \mu \mathrm{l}, 4 \mu \mathrm{l}$, and $5 \mu \mathrm{l}$ of above standard solution was taken into five separate HS vials and crimped immediately to run on HS-GC to plot calibration/linearity curve.

$10 \mathrm{mg}$ of the sample was weighed into HS vial which further crimped and runs it on HS-GC. This sample were processed for chromatogram against calibration plot to know concentration in the sample.

Correlation coefficient was calculated for each component of interest. Results were evaluated as per Table 3 . 
Sample recovery study

$10 \mathrm{mg}$ of Microcrystalline Wax was weighed and put into HS vial which further crimped, this is taken as Blank.

$10 \mathrm{mg}$ of Microcrystalline Wax was weighed another and put into HS vial and spiked with $80 \%, 100 \%$, and 120 target $\%$ of standard, which further crimp and inject in HS-GC for evaluation of relative error \%, which should be $2 \%$ relative standard deviation (RSD) for average response recorded in each concentration injected.

Microcrystalline Wax represents sample matrix and if any Carryover/ Contamination was observed in $\mathrm{M}_{\text {wax }}$ Blank. It should be removed or deducted from spiked one. Results are evaluated as per Table 4.

\section{System precision}

Injected 3 standard Concentration and measure the area response for Relative standard deviations \% described in Table 5.

\section{RESULTS AND DISCUSSION}

Comparison between classic GC experiments HS-GC for essential oil estimations

GC is a traditional method frequently used in the pharmaceutical labs for drug and molecular identification and quantification. Fig. 1a represents GC chromatogram where the run time was $25 \mathrm{~min}$, and elution of each essential oil is at minimum 12.56 and for the maximum was $19.25 \mathrm{~min}$ which is the internal standard peak, which is not used in HS-GC due to precise and accurate reproducibility as compare to GC analysis. The same studies are run on $\mathrm{HS}$ and the elution of oil at minimum retention time - 8.43 and maximum at 11.46 and end with 15 minutes runtime which shows significant improvement in overall 1.6-time reduction in experimental time showed in Fig. 1b for chromatogram correspond to HS. Table 6 represents overall return on investment (ROI) of HS-GC in comparison with GC.

Traditional method required complex preparation procedure using chloroform $\left(\mathrm{CHCl}_{3}\right)$, the present study does not require any solvents for standard and sample preparation. Only direct sampling is exploited in HS vial and treated as per HS conditions described above. By considering the Green analytical approach, solvent elimination is focused and achieved as per ROI document for overall evaluation.

\section{Method validation outcome}

Specificity

Fig. 2 demonstrates the specificity of the method by identification of all essential oil, which was separated from each other having no interference due to blank (Wax) and placebo.

\section{Linearity of response}

The linearity of essential oil has been accessed at the different concentration by injecting $1 \mu \mathrm{l}, 2 \mu \mathrm{l}, 3 \mu \mathrm{l}, 4 \mu \mathrm{l}$, and $5 \mu \mathrm{l}$ range shown in Fig. 3, which was depicted by linear regression analysis revealed correlation coefficients, $r^{2} ;>r^{2}=0.99$.

\section{Accuracy}

Recovery for essential oil was checked at different concentration $(80 \%, 100 \%$, and $120 \%)$ found within the specification limit which is $98 \%$ to $102 \%$ within $<2 \%$ RSD

\section{Precision}

System was checked and found in within acceptable RSD $<5 \%$. Results were shown in Table 5 and overlay of chromatogram described in Fig. 4.

\section{CONCLUSIONS}

On the basis of this study, it appears that the use of this currently developed HS method for the quantification essential oil (EO) is much faster and robust method as compare to classical GC analysis in product formulation area is practical. The time reduction and solvent elimination characteristics of current HS method are very advantageous, compared

Table 3: Linearity curve evaluation

\begin{tabular}{|c|c|c|c|c|c|c|c|}
\hline \multirow[t]{2}{*}{ Analyte a name } & \multirow[t]{2}{*}{ Density $(\mathrm{g} / \mathrm{ml})$} & \multicolumn{5}{|c|}{ Amount of each analyte in standard (mg) } & \multirow[t]{2}{*}{$\mathbf{R}^{2}$ value } \\
\hline & & $1 \mu l$ & $2 \mu l$ & $3 \mu l$ & $4 \mu \mathrm{l}$ & $5 \mu \mathrm{l}$ & \\
\hline Tarpin ka Tel (Pinene) & 0.86 & 0.215 & 0.43 & 0.645 & 0.86 & 1.075 & 0.9975 \\
\hline Pudinah ke Phool (menthol) & 0.89 & 0.2225 & 0.445 & 0.6675 & 0.89 & 1.1125 & 0.9989 \\
\hline Oil of wintergreen (methyl salicylate) & 1.174 & 0.2935 & 0.587 & 0.8805 & 1.174 & 1.4675 & 0.9982 \\
\hline
\end{tabular}

Table 4: Recovery study - represent the recovery of individual essential oils

\begin{tabular}{|c|c|c|c|}
\hline Concentrations $\%$ & Area response & True area theoretical & $\%$ RE \\
\hline 80 & 66235.234 & 67527.928 & 98.09 \\
\hline 100 & 83706.34 & 84409.91 & 99.17 \\
\hline 120 & 99823.624 & 101291.892 & 98.55 \\
\hline \multirow[t]{3}{*}{ Tarpin oil } & & Avg & 98.60 \\
\hline & & SD & 0.54 \\
\hline & & RSD & 0.55 \\
\hline 80 & 50298.345 & 52867.272 & 95.14 \\
\hline 120 & 78329.366 & 79300.908 & 98.77 \\
\hline \multirow{3}{*}{ Nilgiri oil } & & Avg & 97.12 \\
\hline & & SD & 1.84 \\
\hline & & RSD & 1.89 \\
\hline 80 & 59893.76 & 60931.44 & 98.30 \\
\hline 100 & 76054.34 & 76164.3 & 99.86 \\
\hline 120 & 91265.208 & 91397.16 & 99.86 \\
\hline \multirow[t]{2}{*}{ Pudina ke phool } & & Avg & 99.34 \\
\hline & & RSD & 0.91 \\
\hline
\end{tabular}

RE: Relative error, RSD: Relative standard deviation, SD: Standard deviation 


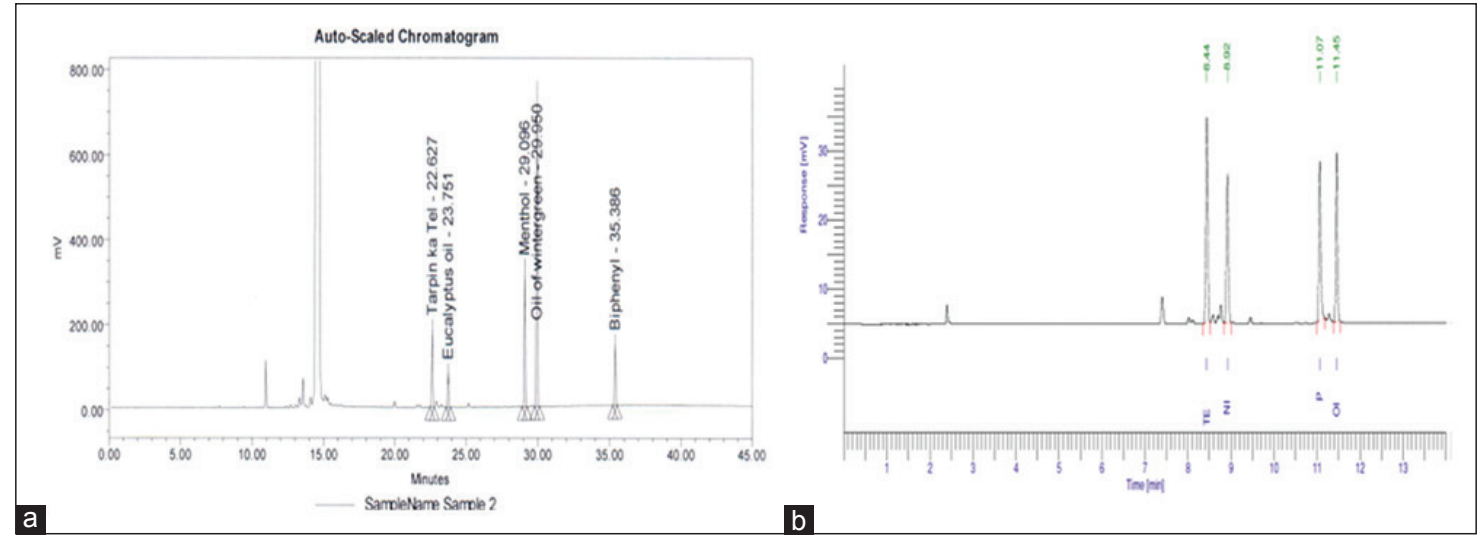

Fig. 1: Gas chromatography (GC) chromatogram of all essential oil by GC-runtime 45 min (a) and by headspace runtime 12 min (b)

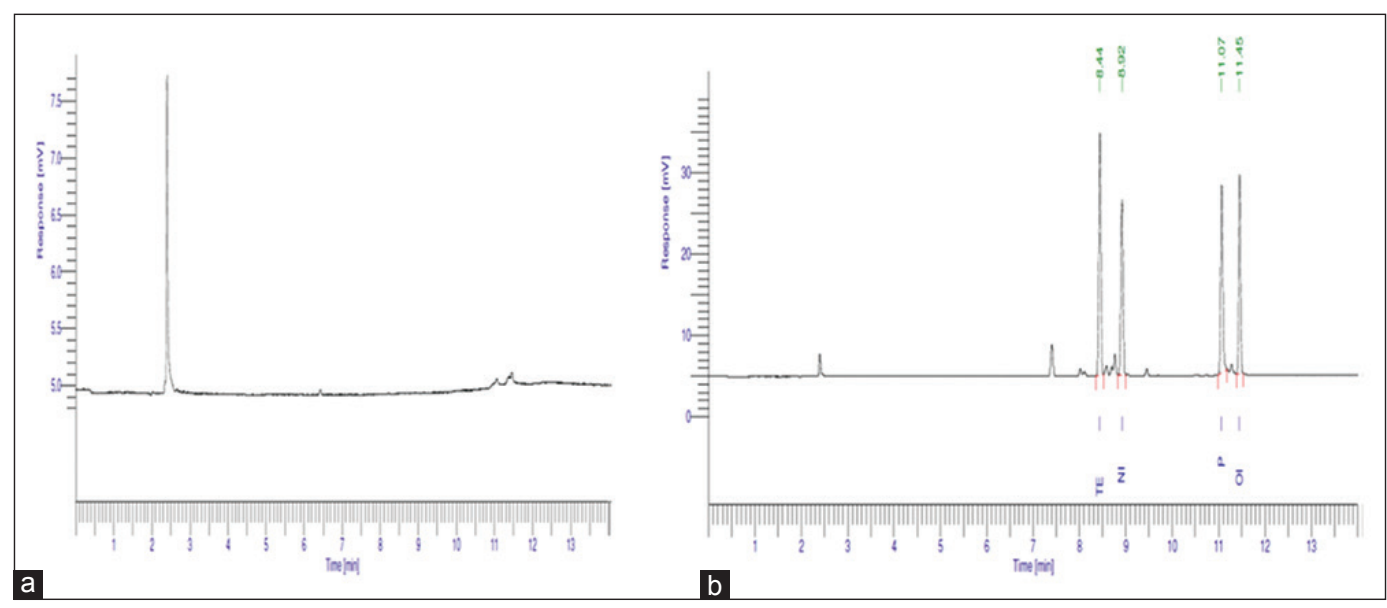

Fig. 2: Sample chromatogram of blank (Wax) (a) and with spiked standard in Wax (b) for specificity

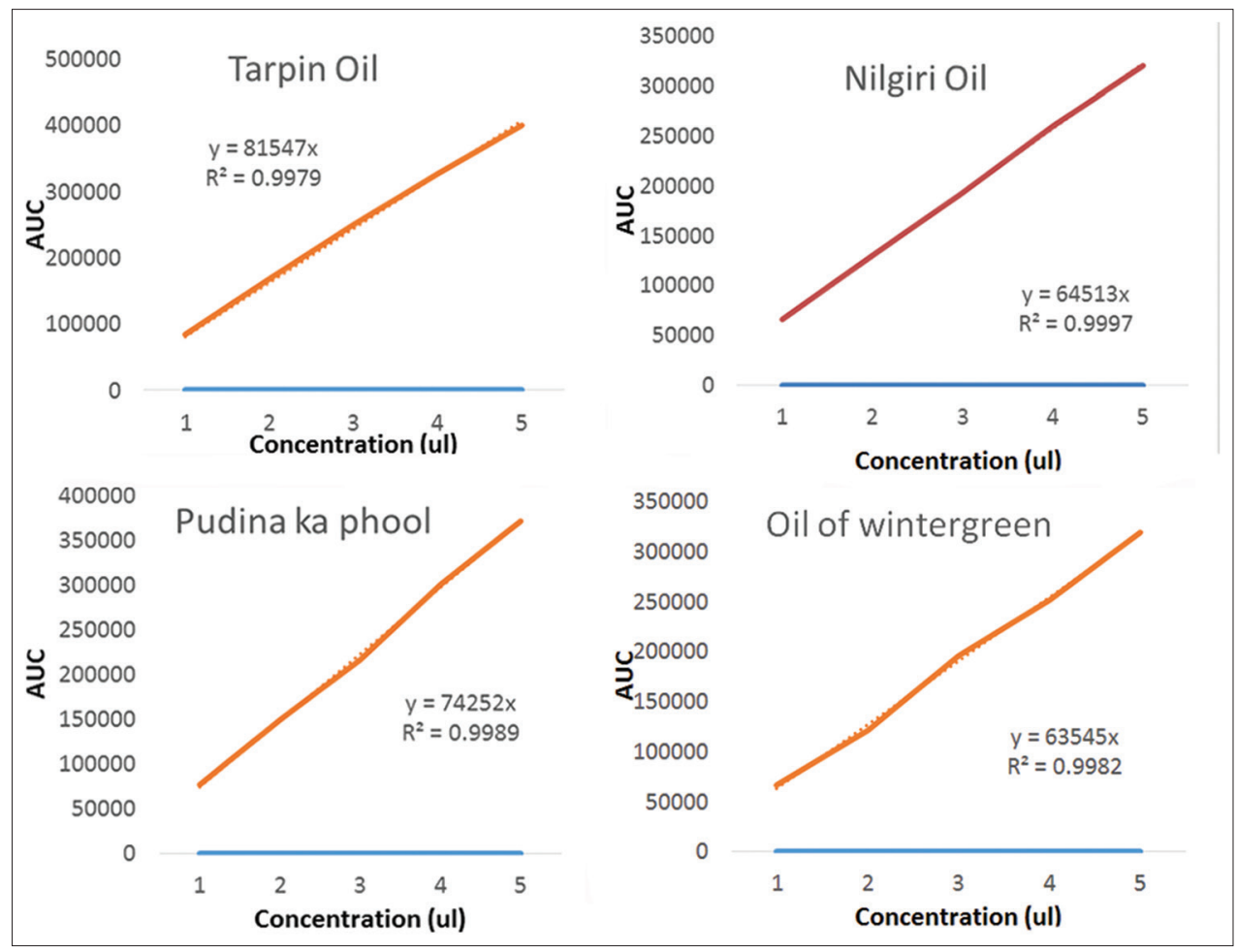

Fig. 3: Showed linearity optimization for all essential oil from 1 ul to $5 \mu$ l concentration 
Table 5: System precision

\begin{tabular}{|c|c|c|c|c|c|c|c|c|}
\hline \multirow[t]{2}{*}{ Inj } & \multicolumn{2}{|c|}{ Terpin ka tel } & \multicolumn{2}{|l|}{ Nilgiri ke tel } & \multicolumn{2}{|c|}{ Pudinah ke phool } & \multicolumn{2}{|c|}{ Oil of wintergreen } \\
\hline & Time (min) & Area $(\mu V . s)$ & Time (min) & Area $(\mu V . s)$ & Time (min) & Area $(\mu V . s)$ & Time (min) & Area $(\mu \mathrm{V} . s)$ \\
\hline STD Inj 1 & 8.44 & 88077.95 & 8.92 & 70555.96 & 11.07 & 70157.04 & 11.46 & 66622.77 \\
\hline STD Inj 2 & 8.44 & 87135.64 & 8.91 & 66000.01 & 11.06 & 71461.64 & 11.45 & 62300.97 \\
\hline STD Inj 3 & 8.44 & 84409.91 & 8.92 & 66084.09 & 11.07 & 76164.30 & 11.46 & 65985.39 \\
\hline Avg & 8.44 & 86541.17 & 8.92 & 67546.69 & 11.07 & 72594.32 & 11.46 & 64969.71 \\
\hline$\%$ RSD & 0.04 & 2.20 & 0.04 & 3.86 & 0.04 & 4.35 & 0.04 & 3.59 \\
\hline
\end{tabular}

RSD: Relative standard deviation

Table 6: Return on investment using HS-GC

\begin{tabular}{llll}
\hline Elements & Traditional GC method & HS-GC & Comments \\
\hline Runtime & $25 \mathrm{~min} /$ injection & $15 \mathrm{~min} /$ injection & In current HS method, runtime is 1.6 times shorter \\
Sample preparation time & $60 \mathrm{~min}$ & $10 \mathrm{~min}$ & No sample preparation. Direct weigh the samples in vial and inject \\
Solvent requirement & $300 \mathrm{ml}$ & No solvents usage & Elimination of chloroform \\
Cost on testing/sample & $750 \mathrm{INR}$ & $150 \mathrm{INR} / \mathrm{sample}$ & 5 times cost effective \\
\hline
\end{tabular}

HS-GC: Head space-gas chromatography

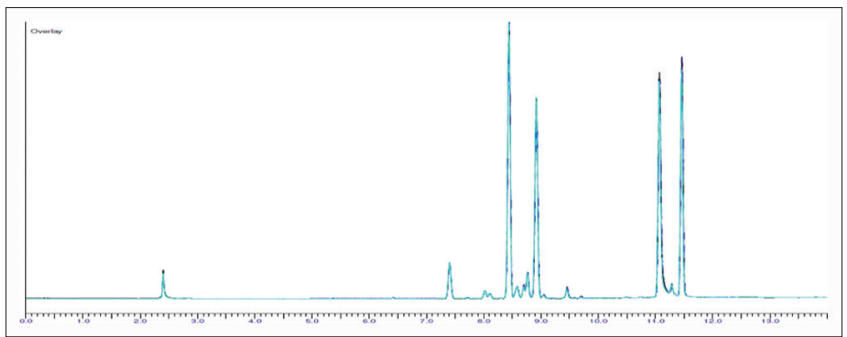

Fig. 4: Overlay chromatogram for system precision

to the most widely used conventional GC technique. Shorter runtime HS-GC method was developed with proper resolution between all peaks.

Direct sample analysis without dilution used for HS sampling. Quantification was done using standard spike method and calculating the response of sample against a standard with the help of density of components as shown in the calculations. Precision was performed for three injections and \% RSD observed not more than 5 .

\section{ACKNOWLEDGMENTS}

The authors are thankful toward Perkin Elmer, India, for providing necessary support.

\section{REFERENCES}

1. Grodowska K, Parczewski A. Organic solvents in the pharmaceutical industry. Acta Pol Pharm 2010;67:3-12.

2. Coutinho ID, Cardoso CA, Ré-Poppi N, Melo AM, Vieira MD, Honda NK, et al. Gas chromatography-mass spectometry (GC-MS) evaluation of antioxidant and antimicrobial activities of essential oil of Campomanesia adamantium (Cambess.) O Berr. (Guavira). Braz J Pharm Sci 2009;45:767-76.
3. Turek C, Stintzing FC. Stability of essential oils: A review. Compr Rev Food Sci Food Saf 2013;12:40-53.

4. Pednekar PP, Vaki BV, Sane RT, Datar AG. Evaluation of antimicrobial and antioxidant activity of stem and leaf extracts of Coscinium fenestratum. Asian J Pharm Clin Res 2013;6:239-42.

5. Pandey S, Pandey P, Kumar R, Singh NP. Antidiabetic and antihyperlipidemic effects of Dillenia indica (L.) leaves extract. Braz J Pharm Sci 2011:47:379-84.

6. Michulec M, Wardencki W. Development of headspace solid-phase microextraction-gas chromatography method for the determination of solvent residues in edible oils and pharmaceuticals. J Chromatogr A 2005; 1071:119-24

7. Gupta A, Singh Y, Srinivas KS, Jain G, Sreekumar VB, Semwal VP. Development and validation of a headspace gas chromatographic method for the determination of residual solvents in arterolane (RBx11160) maleate bulk drug. J Pharm Bioallied Sci 2010;2:32.

8. Snow NH, Slack GC. Headspace analysis in modern gas chromatograph. Trends Anal Chem 2002;21:608-17.

9. Camarasu C, Madichie C, Williams R. Recent progress in the determination of volatile impurities in pharmaceuticals. Trends Anal Chem 2006;25:768-77.

10. Marwa KE, Azza AG. Analysis of three cardiovascular drugs in their ternary mixture using green analytical methodology of smart spectrophotometric methods and RP-HPLC method. Int J Pharm Pharm Sci 2016;8:243-50

11. Bhandari M, Raj S. Practical approach to green chemistry. Int J Pharm Pharm Sci 2017;9:10-26.

12. Hof F, Palmer LC, Rebek J Jr. Synthesis and self-assembly of the "tennis ball" dimer and subsequent encapsulation of methane: An advanced organic chemistry laboratory experiment. J Chem Educ 2001;78:1519.

13. Jun YS, Kang P, Min SS, Lee JM, Kim HK, Seol GH. Effect of eucalyptus oil inhalation on pain and inflammatory responses after total knee replacement: A randomized clinical trial. Evid Based Complement Altern Med 2013;18:502727.

14. Parker D, Martinez C, Stanley C, Simmons J, McIntyre IM. The analysis of methyl salicylate and salicylic acid from Chinese herbal medicine ingestion. J Anal Toxicol 2004;28:214-6.

15. Shah RJ, Patel AI, Vikan IK, Patel NL. Analytical method development and validation of pain relief herbal formulations. Indo Am J Pharm Res 2016;6:5112-7. 